Methods: We included 246 RA patients who met the ACR / EULAR 2010 rheumatoid arthritis classification criteria. We divided the patients into two groups according to the Charlson comorbidity index (scores 0-2 mild,> 2 moderate and severe) (3). We compared the functional status of the two groups assessed by the health assessment questionnaire disability index (HAQ-DI). In addition, we compared disease-related characteristics between groups. We performed the Mann-Whitney $U$ and chi-square tests where appropriate. Lastly, we also adjusted the age when comparing the continuous variables with ANCOVA.

Results: The patients with moderate and severe co-morbidities were older $(p<0.001)$. All other demographic features were similar between the groups. Extra-articular involvement was more frequent in moderate and severe co-morbidity group $(p=0.03)$. All other disease features and treatment modalities were similar between the groups. Additionally, after adjusting the age, none of the continuous features were different between the groups.

Table 1. Disease and demographic features and treatment characteristics of the patients.

\begin{tabular}{lcccc}
\hline & $\begin{array}{c}\text { Mild } \\
\text { co-morbidity } \\
\text { group } \\
\mathbf{( n = 1 8 0 )}\end{array}$ & $\begin{array}{c}\text { Moderate and } \\
\text { severe co- } \\
\text { morbidity } \\
\text { group (n=66) }\end{array}$ & $\mathbf{P}$ & $\begin{array}{c}\mathbf{p}^{* *} \\
\text { (age } \\
\text { adjusted) }\end{array}$ \\
\hline Age (year) & $44.5 \pm 9.2$ & $65.0 \pm 7.0$ & $\mathbf{P}<0.001$ & $\mathrm{~N} / \mathrm{A}$ \\
Gender (M/F) & $34 / 146$ & $16 / 50$ & 0.5 & \\
Smoking (\%) & $24(13.3)$ & $7(10.6)$ & 0.63 & $\mathbf{p}<\mathbf{0 . 0 0 1}$ \\
Charlson co-morbidity index & $1.38 \pm 0.48$ & $3.3 \pm 0.6$ & $\mathbf{p}<0.001$ & 0.23 \\
Disease duration (month) & $65.2 \pm 77.1$ & $65.1 \pm 75.3$ & 0.97 & 0.86 \\
Swollen joint & $0.3 \pm 1.5$ & $0.2 \pm 0.6$ & 0.92 & 0.50 \\
Tender joint & $0.6 \pm 1.6$ & $0.3 \pm 1.0$ & 0.38 & \\
ACPA positivity (\%) & $84(46.6)$ & $29(43.9)$ & 0.92 & \\
RF positivity (\%) & $93(51.6)$ & $66(58.3)$ & 0.39 & 0.37 \\
DAS28-CRP & $2.2 \pm 1.2$ & $2.1 \pm 0.7$ & 0.85 & 0.64 \\
HAQ-DI & $0.16 \pm 0.20$ & $0.27 \pm 0.39$ & 0.05 & \\
Extra-articular involvement (\%) & $3(1.6)$ & $5(7.5)$ & 0.03 & \\
Joint deformity (\%) & $21(11.6)$ & $7(10.6)$ & 077 & 0.48 \\
Number of received DMARD & $1.3 \pm 0.5$ & $1.3 \pm 04$ & 0.55 & 0.60 \\
Steroid dosage (mg) & $1.7 \pm 2.4$ & $1.4 \pm 1.9$ & 0.73 & \\
Ever receiving bDMARD (\%) & $21(11.6)$ & $3(4.5)$ & 0.09 & \\
\hline
\end{tabular}

M: Male; F: Female; ACPA: Anti-Cyclic Citrullinated Peptide Antibody; RF: Rheumatoid factor; DAS-28: Disease activity score-28; HAQ-DI: Health assessment questionnaire disability index; DMARD: Disease modifying drugs; bDMARD: Biologic disease modifying drugs. ${ }^{\star \star} F o r$ continuous variables. Continuous variables shown as Mean \pm SD. $p<0.05$ is significant

Conclusion: The only different disease feature was the increased frequency of extra-articular involvement in the more severe co-morbidity group. All other disease characteristics were similar. In addition, the severity of the co-morbidities may not change the doctors' decision to prescribe biological or synthetic DMARDs and steroid dosage.

REFERENCES:

[1] Dougados M, Soubrier M, Antunez A, et al. Prevalence of comorbidities in rheumatoid arthritis and evaluation of their monitoring: results of an international, cross-sectional study (COMORA). Ann Rheum Dis 2014; 73:62-8.

[2]Luque Ramos A, Redeker I, Hoffmann F, et al. Comorbidities in Patients with Rheumatoid Arthritis and Their Association with Patient-reported Outcomes: Results of Claims Data Linked to Questionnaire Survey. J Rheumatol 2019; 46:564-571.

[3] D'Hoore W, Sicotte C, and Tilquin C. Risk adjustment in outcome assessment: the Charlson comorbidity index. Methods Inf Med 1993; 32:382-7.

Disclosure of Interests: None declared

DOI: 10.1136/annrheumdis-2021-eular.2903

\section{POS0561 OBESITY PHENOTYPES IN EARLY RHEUMATOID ARTHRITIS}

Y. Gorbunova ${ }^{1}$, T. Popkova $^{1}$, L. Kondrateva ${ }^{1}$, M. Cherkasova ${ }^{2}$, E. Nasonov ${ }^{3}$, A. Lila ${ }^{3} .^{1}$ VA Nasonova Research Institute of Rheumatology, Laboratory of Systemic Rheumatic Diseases, Moskva, Russian Federation; ${ }^{2}$ VA Nasonova Research Institute of Rheumatology, Laboratory of Immunology, Moskva, Russian Federation; ${ }^{3}$ VA Nasonova Research Institute of Rheumatology, Scientific Department, Moskva, Russian Federation

Background: Patients with rheumatoid arthritis (RA) and obesity have a lower risk of early death than patients with normal weight due to the so-called "obesity paradox". Available publications discuss three phenotypes of obesity: classical obesity, metabolically healthy overweight/obesity, and latent obesity (normal weight associated with metabolic disorders, most importantly - with insulin resistance and adipocytokines imbalance).

Objectives: To clarify the prevalence of obesity phenotypes and to identify factors predisposing to «latent obesity» in early RA without diabetes mellitus or hyperglycemia.

Methods: The study included 35 pts ( 23 women, 12 men) with early RA (criteria ACR / EULAR, 2010), 56 [43,0; 60,0] years old, naïve to treatment with glucocorticoids and disease-modifying anti-rheumatics, without established diabetes mellitus. Pts were seropositive for IgM RF and anti-CCP, with highly active RA (DAS28 5,9 [5,2; 6,4]; SDAI 35,4 [27,0; 45,8], and CDAI 31,0 [26,0; 44,0]) scores, and median disease duration of 8.0 [6,0;15.0] months. Electrochemiluminescence assay Elecsys (Roche Diagnostics) was used to measure patients' insulin levels, and ELISA (DBS - Diagnostics Biochem Canada Inc.) - for evaluation of serum leptin concentrations. Insulin resistance (IR) was defined as Homeostasis Model Assessment of Insulin Resistance index $(\mathrm{HOMA}-\mathrm{IR}) \geq 2,77$. Leptin levels were considered elevated at values $\geq 11,1 \mathrm{ng} /$ $\mathrm{ml}$ for women, $\geq 5,6 \mathrm{ng} / \mathrm{ml}$ for men. The overweight/obesity status was determined by World Health Organization criteria in pts with body mass index $(\mathrm{BMI}) \geq 25 \mathrm{~kg} / \mathrm{m}^{2}$.

Results: Overweight/obesity were documented in 19 (54, 3\%) pts with early RA $4 / 19(21 \%)$ had high leptin levels and IR, 11/19 (58\%) had isolated hyperleptinemia. Normal BMI was found in $16(45,7 \%)$ pts with early RA, 2/16 (12,5\%) had elevated leptin levels and IR, and 6/16 (37,5\%) - only hyperleptinemia. Four (21\%) out of 19 overweight and $8(50 \%)$ out of 16 pts with normal BMI did not show any metabolic disorders $(p=0,02)$. Classical obesity was found in $15(43 \%)$ and latent obesity - in $8(23 \%)$ pts with early RA. Leptin levels correlated with waist circumference $(r=0,58, p=0,02)$, BMI $(r=0,71, p=0,0006)$, ESR $(r=0,5$, $p=0,02)$ in the overweight/obese pts, and with waist circumference $(r=0,59$ $p=0,03)$, IgM RF $(r=0,58, p=0,03)$, triglyceride levels $(r=0,77, p=0,003)$, and atherogenic index $(r=0,62, p=0,03)$ in pts with normal weight.

Conclusion: The classical obesity phenotype associated with abdominal obesity and inflammation was the most common and prevailing over other phenotypes in early RA. Latent obesity was less common and was associated with an unfavorable lipid profile and accumulation of abdominal fat, therefore increasing the risk of cardiovascular diseases in RA. Metabolically healthy overweight/obesity in early RA was really a rare phenotype.

Disclosure of Interests: None declared

DOI: 10.1136/annrheumdis-2021-eular.2961

\section{POS0562 PULSE PRESSURE AS AN INDICATOR OF SUBCLINICAL ATHEROSCLEROSIS IN RHEUMATOID ARTHRITIS}

S. Lugo-Perez ${ }^{1}$, I. J. Colunga-Pedraza ${ }^{2}$, J. R. Azpiri-López ${ }^{1}$, D. Á. GalarzaDelgado $^{2}$, N. Guajardo-Jauregui ${ }^{2}$, A. B. Rodriguez-Romero ${ }^{2}$, A. Cárdenas ${ }^{2}$, A. C. Garza Acosta ${ }^{3}$. 'Hospital Universitario "Dr. José Eleuterio González", Universidad Autónoma de Nuevo León, Cardiology, Monterrey, Mexico; ${ }^{2}$ Hospital Universitario “Dr. José Eleuterio González”, Universidad Autónoma de Nuevo León, Rheumatology, Monterrey, Mexico; ${ }^{3}$ Hospital Universitario "Dr. José Eleuterio González", Universidad Autónoma de Nuevo León, Radiology, Monterrey, Mexico

Background: Pulse pressure (PP) is defined as the difference between systolic and diastolic blood pressure and represents arterial compliance and reflective properties of blood flow (1). It is well known that gender, age, and race / ethnicity are intrinsic factors of the patient that influence PP. Brachial PP has recently been associated with markers of subclinical cardiovascular disease after adjustment with traditional cardiovascular risk factors in the general population (2). However, this relationship has not been studied in patients with rheumatoid arthritis (RA) and its identification would allow earlier adjustments of cardiovascular therapies in this high-risk group. Objectives: The aim of the study is to analyze the difference in PP between patients with RA and healthy controls. Additionally, to analyze the difference between patients with carotid plaque $(\mathrm{CP})$ and without $\mathrm{CP}$.

Methods: A cross-sectional, observational, and comparative study of ninety-two patients with RA aged 40-75 years and who fulfilled ACR/EULAR 2010 classification criteria. Also, we included ninety-two controls without RA, matched by gender, age and comorbidities. A carotid ultrasound was performed in patients with $\mathrm{RA}$ and it was divided into two subgroups, with the presence of $\mathrm{CP}$ and without CP. A blood pressure measurement was taken after 15 minutes of rest on the right arm of all patients. Distribution was evaluated with the Kolmogorov-Smirnov test. Descriptive analysis was done using measures of central tendency. Chi square, Student's t test and Mann-Whitney $U$ test were used for comparations between groups. A $p$ value $<0.05$ was considered statistically significant.

Results: We found no statistical difference between groups regarding age, gender and, comorbidities (type 2 diabetes mellitus, hypertension, dyslipidemia and, active smoking) (Table 1). There was a significant difference in PP between patients with $\mathrm{RA}$ and controls ( $50 \mathrm{mmHg}$ vs $41 \mathrm{mmHg}$ respectively, $p=0.032$ ). Patients with RA had a significant difference in PP of patients with $\mathrm{CP}$ and without $\mathrm{CP}(50 \mathrm{mmHg}$ vs $44 \mathrm{mmHg}$ respectively, $p=0.008$ ) (Figure 1). When performing a binary logistic regression, it was found that $\mathrm{PP}$ was the only independent factor for the presence of $\mathrm{CP}$ in patients with RA, OR $1.054(95 \% \mathrm{Cl} 1.008-1.101, p=0.020)$

Conclusion: Patients with RA had a higher PP than controls. Binary logistic regression showed $\mathrm{PP}$ as the only independent factor for the presence of subclinical atherosclerosis in patients with RA. PP is a parameter that all rheumatologists should consider when evaluating cardiovascular risk in patients with RA. REFERENCES:

[1] Winston GJ, Palmas W, Lima J, et al. Pulse pressure and subclinical cardiovascular disease in the multi-ethnic study of atherosclerosis. Am J Hypertens 2013;26(5):636-42. doi: 10.1093/ajh/hps092 
[2] Zureik M, Touboul PJ, Bonithon-Kopp C, et al. Cross-sectional and 4-year longitudinal associations between brachial pulse pressure and common carotid intima-media thickness in a general population. The EVA study. Stroke 1999;30(3):550-5. doi: 10.1161/01.str.30.3.550

Table 1. Demographic characteristics.

\begin{tabular}{|c|c|c|c|}
\hline & RA (n=92) & Control $(n=92)$ & $p$ \\
\hline Women, n (\%) & $85(92.4)$ & $85(92.4)$ & NS \\
\hline Age, years \pm SD & $58.0(55.0-63.0)$ & $56.5(54.0-61.0)$ & NS \\
\hline T2DM, n (\%) & $17(18.5)$ & $15(16.3)$ & NS \\
\hline Hypertension, n (\%) & 33 (35.9) & $33(35.9)$ & NS \\
\hline Dyslipidemia, $n(\%)$ & $30(32.6)$ & $29(31.5)$ & NS \\
\hline Obesity, n (\%) & $30(32.6)$ & 31 (33.7) & NS \\
\hline \multirow[t]{2}{*}{ Active smoking, n (\%) } & $11(12.0)$ & $20(21.7)$ & NS \\
\hline & $\begin{array}{c}\text { RA patients with CP } \\
(n=39)\end{array}$ & RA patients without & $p$ \\
\hline Women, n (\%) & $36(92.3)$ & $49(92.5)$ & NS \\
\hline Age, years $\pm S D$ & $60.13 \pm 5.98$ & $58.08 \pm 7.00$ & NS \\
\hline T2DM, n (\%) & $9(23.1)$ & $8(15.1)$ & NS \\
\hline Hypertension, n (\%) & $16(41.0)$ & $17(32.1)$ & NS \\
\hline Dyslipidemia, n (\%) & $13(33.3)$ & 17 (32.1) & NS \\
\hline Obesity, n (\%) & 15 (38.5) & 15 (28.3) & NS \\
\hline Active smoking, $n(\%)$ & $6(15.4)$ & $5(9.4)$ & NS \\
\hline Disease duration, years & $8.44(3.00-15.50)$ & $12.86(4.66-19.66)$ & NS \\
\hline
\end{tabular}

NS, no significant; T2DM, type 2 diabetes mellitus; CP, carotid plaque.

Figure 1. Comparison of pulse pressure between RA and controls and, RA with and without carotid plaque

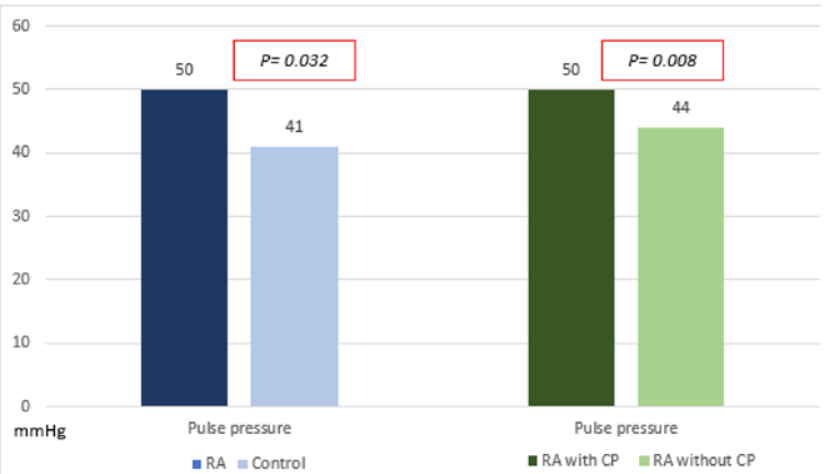

Disclosure of Interests: None declared

DOI: 10.1136/annrheumdis-2021-eular.3005

\section{POS0563 1 THE NATURAL COURSE OF RHEUMATOID ARTHRITIS- ASSOCIATED INTERSTITIAL LUNG DISEASE FOCUSING ON LUNG PHYSIOLOGY AND DISEASE ACTIVITY: A PROSPECTIVE COHORT STUDY (PART 2)}

S. H. Chang ${ }^{1}$, J. S. Lee' ${ }^{2}$, J. S. Lee ${ }^{3}$, C. H. Park ${ }^{4}$, M. U. Kim ${ }^{5}$, Y. J. Ha ${ }^{6}$, E. H. Kang ${ }^{6}$, Y. A. Lee ${ }^{7}$, Y. Park ${ }^{8}$, J. Y. Choe ${ }^{9}$, E. Y. Lee ${ }^{10}$ on behalf of KOrean Rheumatoid Arthritis Interstitial Lung disease (KORAIL) cohort study group. ${ }^{1}$ Soonchunhyang University College of Medicine, Division of Rheumatology, Department of Internal Medicine, Cheonan, Korea, Rep. of (South Korea); ${ }^{2}$ Clinical Research Center, Asan Institute for Life Sciences, Asan Medical Center, Department of Medical Stastics, Seoul, Korea, Rep. of (South Korea); ${ }^{3}$ GENOME INSIGHT Inc., -, Seoul, Korea, Rep. of (South Korea); ${ }^{4}$ Soonchunhyang University College of Medicine, Department of Radiology, Cheonan, Korea, Rep. of (South Korea); ${ }^{5}$ SMG-SNU Boramae Medical Center, Department of Radiology, Seoul, Korea, Rep. of (South Korea): ' 6 Seoul National University Bundang Hospital, Division of Rheumatology, Department of Internal Medicine, Seongnam, Korea, Rep. of (South Korea); ${ }^{7}$ Kyung Hee University College of Medicine, Division of Rheumatology, Department of Internal Medicine, Seoul, Korea, Rep. of (South Korea); ${ }^{8}$ Yonsei University College of Medicine, Division of Rheumatology, Department of Internal Medicine, Seoul, Korea, Rep. of (South Korea); ${ }^{9}$ Catholic University of Daegu College of Medicine, Division of Rheumatology, Department of Internal Medicine, Daegu, Korea, Rep. of (South Korea); ${ }^{10}$ Seoul National University College of Medicine, Division of Rheumatology, Department of Internal Medicine, Seoul, Korea, Rep. of (South Korea)

Background: Interstitial lung disease (ILD) is a severe extra-articular manifestation of rheumatoid arthritis (RA). However, the effect of RA disease activity on the course of ILD is not yet known.

Objectives: To assess the natural course of lung physiology of RA-ILD and the relation between arthritis activity and pulmonary physiology in patients with RA-ILD.
Methods: The Korean Rheumatoid Arthritis ILd (KORAIL) cohort is the prospective observational cohort and aims to investigate the natural course of RAILD. Based on either 1987 or 2020 ACR criteria, patients diagnosed with RA and ILD based on CT scan were recruited from six tertiary medical hospitals in Korea since January 2015. RA disease activity was assessed using disease activity (DAS)28-ESR and CRP, annually. Pulmonary function tests (PFT), including FVC and DLCO were conducted annually. According to the transition of DAS28-ESR status, we classified patients into four groups: Group A. persistent remission or low disease activity, Group B. improvement, Group C. worsening, Group D. persistent moderate to high disease activity.

Results: We analyzed 143 patients who completed a 2-year follow-up (visit 2) or had died with available PFT results at least twice. Mean duration since RA diagnosis and since ILD diagnosis was $7.6 \pm 8.0$ and $2.7 \pm 3.1$ years, respectively. Twenty-four patients were Group A, 33 Group B, 10 Group C and 30 Group D. The mean of $F V C(\mathrm{~mL})$ and \% of the predicted value in $\mathrm{FVC}$ was significantly lower in Group D than in other groups (Table 1). The annual rate of decline in FVC was $-42(95 \% \mathrm{Cl}-93 \sim 10) \mathrm{mL}^{-y e a r^{-1}}$ in Group B while $-113(95 \% \mathrm{Cl}-206$ 21) $\mathrm{mL} \cdot$ year $^{-1}$ in Group $C$ (Figure 1A). The annual decline rate in Group $C$ was further exaggerated in patients with $\geq 80 \%$ of FVC predicted $(-141,95 \% \mathrm{Cl}$ $\left.-251 \sim 32 \mathrm{~mL} \cdot \mathrm{year}^{-1}\right)$. During two years of follow-up, patients ever experienced a relative decline of $\geq 10 \%$ from the enrollment in FVC predicted was $27.3 \%(n-9 / 33)$ in Group B whereas $30.0 \%(3 / 10)$ in Group C. The annual rate of decline in \% of DLco predicted value was also the largest in Group C $\left(-4.6 \%\right.$.year ${ }^{-1}, 95 \% \mathrm{Cl}$ $-8.5 \sim-0.7)$, which further exaggerated in patients with $\geq 80 \%$ of FVC predicted $\left(-4.9 \% \cdot\right.$ year $^{-1}, 95 \% \mathrm{Cl}-8.3 \sim-1.5$, Figure 1B). Of note, about half of patients with maintained not only low disease activity (Group A) but also moderate to severe disease activity (Group D) improved in DLco at least $10 \%$ or more from the enrollment of DLco predicted value (Group A: $54.2 \%, n=13 / 24$, Group D: $46.7 \%$, $n=14 / 30$ )

Conclusion: RA disease activity is associated with the change of lung physiology in patients with RA-ILD; worsening disease activity associated with a further decrease of annual change in FVC and maintaining low disease activity associated with a further increase of annual change in $\%$ of DLco predicted value.

Table 1. The analysis of forced vital capacity (FVC) according to disease activity transition group.

\begin{tabular}{|c|c|c|c|c|}
\hline & Group A & Group B & Group C & Group D \\
\hline $\mathrm{FVC}(\mathrm{mL}), \mathrm{mean} \pm \mathrm{SD}$ & $2810.0 \pm 771.1$ & $2528.8 \pm 735.3$ & $2801.0 \pm 952.7$ & $2048.3 \pm 575.7$ \\
\hline FVC $\%$ of predicted, mean \pm SD & $87.5 \pm 14.5$ & $86.5 \pm 16.6$ & $93.0 \pm 15.6$ & $77.2 \pm 17.3$ \\
\hline $\begin{array}{l}\text { Rate of FVC decline, } \mathrm{mL} \cdot \mathrm{year}^{-1} \\
\qquad(95 \% \mathrm{Cl})\end{array}$ & $-52(-112,7)$ & $-42(-93,10)$ & $-113(-206,-21)$ & $1(-52,54)$ \\
\hline $\begin{array}{l}\text { A 10-point decline from V1 in } \\
\text { predicted FVC value, } n(\%)\end{array}$ & $29(20.3)$ & $6(25.0)$ & $6(18.2)$ & $3(30.0)$ \\
\hline $\begin{array}{l}\text { Relative decline of } 10 \% \text { from the } \\
\text { enrollment in predicted FVC } \\
\text { value, } n(\%)\end{array}$ & $35(24.5)$ & $5(20.8)$ & $9(27.3)$ & $3(30.0)$ \\
\hline
\end{tabular}
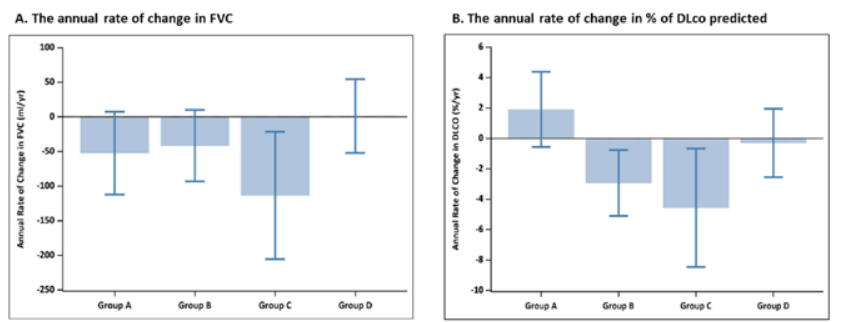

Figure 1. The annual change of pulmonary physiology according to disease activity transition group.

Acknowledgements: This work was supported by the Korea Health Technology R\&D Project through the Korea Health Industry Development Institute, funded by the Ministry of Health and Welfare, Republic of Korea (grant no.HI14C1277). Disclosure of Interests: None declared

DOI: 10.1136/annrheumdis-2021-eular.3084

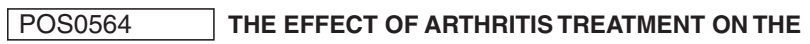 COURSE OF RHEUMATOID ARTHRITIS-ASSOCIATED INTERSTITIAL LUNG DISEASE FOCUSING ON BIOLOGIC DMARDS: FROM A PROSPECTIVE COHORT STUDY (PART 5)}

S. H. Chang ${ }^{1}$, J. S. Lee ${ }^{2}$, J. S. Lee ${ }^{3}$, C. H. Park ${ }^{4}$, M. U. Kim ${ }^{5}$, Y. J. Ha ${ }^{6}$, E. H. Kang ${ }^{6}$, Y. A. Lee ${ }^{7}$, Y. Park ${ }^{8}$, J.Y. Choe ${ }^{9}$, E. Y. Lee ${ }^{10}$ on behalf of KOrean Rheumatoid Arthritis Interstitial Lung disease (KORAIL) cohort study group. 